\title{
Pakistani LIS Scholars' Altmetrics in ResearchGate
}

\author{
Abstract \\ Purpose - The purpose of this paper is to analyse the research performance of Pakistani \\ library and information science (LIS) scholars, using the altmetrics provided by \\ ResearchGate.
}

Design/methodology/approach - Purposive sampling was used to collect profiles between 15 January 2015 and 30 April 2016 of all members of ResearchGate who had self-identified as an LIS scholar of Pakistani nationality. Additional demographic data was obtained through a small survey administered via Google Docs. Resultant data was analysed in SPSS version 21.

Findings - Study results were broadly consistent in terms of demographical data with previous studies of this cohort. There was a positive correlation between publications, reads and citations for scholars who had recorded at least one publication. The majority of publications had not been published in a high impact factor journal. Academic networking site profiles create the potential for collaboration, building connections, and exchanging information.

Research limitations/implications - Some scholars eliminated from this study may have published at least one output but neglected to upload details to ResearchGate. It is a purposive, exploratory study that provides insights into future research.

Practical implications - The paper produces findings of relevance to researchers in other countries and / or disciplines who may wish to conduct a similar study of a defined cohort.

Originality/value - There have been no previous published research studies on altmetrics associated with Pakistani LIS scholars.

Keywords: LIS researcher, Academic social networking, Research impact, Researcher profile, Altmetrics, ResearchGate

Article Classification: Research paper

\section{Introduction}

Scholarly communication is generally depicted as an ecosystem which describes the processes involved in the creation, publication, dissemination, and discovery of scholarly research. Technological innovations, along with efforts to increase access to scholarship, have given rise to a landscape in which evolving systems present opportunities for research to be shared not only more broadly but also more rapidly.

Mas-Bleda et al. (2014) have postulated three types of "web presences": personal, institutional and social. Social web presences are platforms which allow researchers to provide their research outputs either automatically, e.g. Google Scholar and Microsoft Academic Search (MAS) or by self-entry, e.g. Mendeley, Academia.edu, and ResearchGate (Yu et al., 2015). It is this latter category, and in particular ResearchGate, which is the focus of this paper.

The current thinking is that the traditional forms of scholarly communication - lengthy peer review processes; published research that remains based on a model of paper-based journals, including static article formats and barriers to read and reuse research; and subscription costs - actually hinder the sharing of research results in a timely and meaningful way, especially with those who most lack access and would most benefit (Sample, 2012; Newton, 2013; Phillips, 2013). At the same time, concern is being 
expressed that "the impact of a scholar's work has often been assessed by, or with the aid of, the number of citations to their publications from other scientific publications, often extracted from the Web of Science (WoS) or Scopus” (Mas-Bleda et al., 2014, p. 338). That is to say, measuring research impact based solely on traditional forms of publishing may not provide a full picture of the potential impact of a research output.

Given these constraints, not surprisingly, researchers have augmented their channels of dissemination through the use of the web, by participating in online communities, forums and social media networks (Kadriu, 2013). Nielsen (2012) and Nentwich and König (2012) have outlined how researchers are using the power of the Internet not only to expand their problem-solving capability but also to generate new forms of scholarly communication. According to Hoffmann et al. (2016, p. 766), the "co-authorship of research collaboration is easier to organize and more common than two decades ago".

With the increased attention being paid to new communication channels used by scholars, there is the potential to gain new insights into the ways in which scholars engage with them. This paper reports on an analysis of the profiles of Pakistani LIS scholars who are members of ResearchGate, an academic social networking site. For the purposes of this paper, the authors have used the term "scholar" to encompass academics, researchers, and professionals.

Section 1 introduces new channels of disseminating research outputs. Section 2 presents a review of the literature to help contextualise the study: bibliometrics and altmetrics; academic social networking sites, with particular reference to ResearchGate; and statistical analyses to date of Pakistani library and information science scholars. Section 3 outlines the principal research objectives. The methodology of how the research was conducted is explained in Section 4, while the succeeding section provides results derived from this study. Discussion of the results is presented in Section 6, along with suggested areas for future research. Section 7 summarises the authors' conclusions.

\section{Related research}

\subsection{Bibliometric and altmetrics}

Traditionally bibliometrics, which encompasses the statistical analysis of written publications, has long been used as one of the key tools in measuring and assessing the research impact of individuals, groups of individuals or institutions (Groos and Pritchard, 1969, p. 348; Goodyear et al., 2009; Durieux and Gevenois, 2010; Yu et al., 2015). Using a citation-based approach, the assumption is that if an article is published in a journal with a high impact factor, which is determined in part by the number of citations to articles within that journal, this will raise the publishing profile of the author. The number of citations to that article over time is considered to also be a key measure of the productivity and the impact of that scholar.

However, the emergence of the Open Access movement and advances in digital publishing have given rise to new impact indicators, which have been designed to better capture this changing landscape (Li et al., 2011; Priem et al., 2012; Roemer and Borchardt, 2012; Haustein et al., 2014; Wildgaard et al., 2014; Veletsianos, 2016). A report commissioned by the Higher Education Funding Council for England (HEFCE) has noted the advent of altmetrics, i.e. non-traditional metrics that cover not just citation counts but also downloads, social media shares and other measures of impact of research outputs (Wilsdon et al., 2015, p. 5). Importantly the report highlights: "The rise of new social media has created an additional stream of work under the label altmetrics. These are 
indicators derived from social websites, such as Twitter, Academia.edu, Mendeley, and ResearchGate, with data that can be gathered automatically by computer programs” (p. 56). Ortega (2015c, p. 47) suggests that whereas altmetrics may not be a good proxy for research evaluation, they could be used as a proxy for the social impact of science.

Academic social networking sites are an important source of altmetrics.

\subsection{Academic social networking sites}

A social network site has been defined as:

[...] a networked communication platform in which participants 1) have uniquely identifiable profiles that consist of user-supplied content, content provided by other users, and/or system-provided data; 2) can publicly articulate connections that can be viewed and traversed by others; and 3) can consume, produce, and/or interact with streams of user-generated content provided by their connections on the site (Ellison and Boyd, 2013, p. 158).

A number of social networking platforms are aimed specifically at the academic community. Popular examples include, but are not limited to, academic social networking sites (ASNS) such as Academia.edu, Mendeley, and ResearchGate. These offer mechanisms for sharing information or research, connecting with peers, and creating a personal profile (Giglia, 2011). Espinoza Vasquez and Caicedo Bastidas (2015, p. 1) have identified five broad services provided by ASNS: “(1) collaboration, (2) online persona management, (3) research dissemination, (4) documents management, and (5) impact measurement”.

Ovadia (2014, p. 167) notes that "Academic social networking sites allow a certain responsiveness and informality that is not possible with the formal publishing process". For example, members may be able to draw upon crowd-sourcing functionality to raise problems as well contact other scholars with similar interests.

Given that in recent years ASNS have begun to be used more actively by scholars to promote their research and to interact with other researchers, an increasing number of publications have been written about the relative merits and advantages of ASNS (Ovadia, 2014; Thelwall and Kousha, 2014; Thelwall and Kousha, 2014b; Nicholas et al., 2015; Thelwall and Kousha, 2015). Positive factors include "opportunities to create dialogue that may lead to collaborative research" (Crawford, 2011, p. 736), increase in co-authorship of research collaboration (Hoffman et al., 2015, p. 766), and the ability to "provide measures of academic impact" (Espinoza Vasquez and Caicedo Bastidas, 2015, p. 2). In addition, Gardner and Inger (2016, p. 9) have reported that "Social media sites appear to be a significant source of free articles in lower income countries".

At the same time, concerned scholars have discussed, among other topics, the legality of uploading research outputs (Howard, 2013), the lack of longitudinal data on the use of ASNS over time (Hoffmann et al., 2016, p. 773), and the lack of clarity regarding the basis for generating some of the altmetrics associated with ASNS, e.g. ResearchGate (Thelwall and Kousha, 2015, p. 880).

In terms of the metrics provided by ASNS, according to Mikki et al. (2015, p. 3/17), the most common metrics are those "based on number of publications, citations, views, downloads, following, followers and co-authors". The uniqueness of ResearchGate lies in its use of its own ResearchGate Score (RGScore) and, until mid-2016, Impact Points.

\subsection{ResearchGate}

ResearchGate (RG) was initially launched in 2008 by two physicians--Dr. Ijad Madisch and 
Dr. Sören Hofmayer--and a computer scientist, Horst Fickenscher, to facilitate international collaboration among researchers. Its original stated mission was to "connect researchers and make it easy for them to share and access scientific output, knowledge, and expertise". As of December 2016, it had more than 11 million members (https://www.researchgate.net/about).

Each member has a profile page which provides fields for entering brief biographical information as well as publications; the latter covers a wide range of outputs, from articles to data to working papers. Publications are listed under the broader category of "Contributions", which includes not only number of citations (based only on the publications in the RG database) but also the number of instances in which a member has interacted with the RG community in different types of activities, e.g. posing questions and answering other researchers' questions. Additional information pertinent to a member, such as relevant skills and expertise along with topics / trends which they are following within the ResearchGate database, is displayed under the broad category of "Information”.

ResearchGate records statistics for profile views, along with the number of reads and citations for those publications listed within ResearchGate by the member. In addition, it offers several "scores": $h$-index and RG score. The RG $h$-index uses the same algorithm as Hirsch's $h$-index but is limited to the content of its own database. It no longer offers "impact points”, which appear to have been based on Thomson Reuter's Web of Knowledge database. The RG score is "calculated based on the publications in your profile and how other researchers interact with your content" (https://www.researchgate.net/publicprofile.RGScoreFAQ.html).

It should be noted that ResearchGate provides statistics not only for individual members but also for institutions, which it does by summing the RG Scores of their individual members using ResearchGate. However, a discussion of the institutional aspect of ResearchGate is out of scope for this paper.

Given the uptake and relative popularity of ResearchGate (Van Noorden, 2014; Ortega, 2015c; Elsayad, 2016), it is not surprising that a number of scholarly articles have been devoted to this particular ASNS. In a 2013 article, for example, Garcia-Milian and Norton have outlined the use of ResearchGate by a University of Florida biomedical sciences librarian to provide asynchronous reference support to a cohort of university-affiliated researchers. Goodwin et al. (2014, p. [4]) have concluded that ResearchGate "has provided a low barrier to use for newcomers unlike other social media platforms”. Based on the results of a study of supply chain management researchers, Yu et al. (2016) have reported that (1) the RG score demonstrated potential as an alternative performance indicator for academic institutions and (2) the RG score could be an "an effective indicator for measuring an individual researcher's performance” (p. 1005). While ruling out the use of ResearchGate data for "formal evaluations", Thelwall and Kousha (2016, p. 10-11) suggest that ResearchGate "views" are a "promising potential source of readership evidence for academic articles”.

Concurrently a number of scholars have criticised ResearchGate for its lack of transparency. Kraker et al. (2015) refer to the site as "a sort of black-box evaluation machine that keeps researchers guessing, which actions are taken into account when their reputation is measured". Kraker and Lex (2015, p. [2]) elaborate: "ResearchGate does not hide the fact that it modifies its algorithm and the data sources being considered along the way. The problem with the way that ResearchGate handles this process is that it is not transparent and that there is no way to reconstruct it. This makes it impossible to compare the RG scores over time, further limiting its usefulness.” As a result, ResearchGate would not currently comply with the proposed draft NISO Altmetrics Data Quality Code of Conduct, specifically recommendation number 12: "Provide a process by which data can be independently 
verified” (National Information Standards Organization, 2016, p. 6).

Notwithstanding its shortcomings, ResearchGate has been discussed in a range of recent studies regarding specific cohorts, either as part of a wider investigation of the use of ASNS in general or as part of a more targeted investigation. In India, whereas Madhusudan (2012) has examined how scholars use ASNS at the University of Delhi, Chakraborty (2012) has compared the use of Facebook with ResearchGate by scholars at North Eastern Hill University, and Mahajan et al. (2013) have compared the purposes for using ASNS by scholars at Panjab University with those of scholars at Chandigarh and Kurukshetra University.

Ortega (2015a, p. 520) has used members of the Spanish National Research Council as the basis for analysing "the disciplinary performance of a same sample of researchers on a varied number of academic social sites, comparing their numbers across web sites”. Kadriu (2013) has examined the profiles of those scholars at South East European University, Macedonia, who are members of ResearchGate, to determine the presence of any "collaborative networks" among this discrete group. Asnafi et al. (2015) have reported on the use of ResearchGate at three major Iranian universities. Hoffmann et al. (2016) have used data for faculty members of the School of Management at a Swiss university to identify the nature of the relationship of members' interactions on ResearchGate with traditional, offline impact indicators. Yu et al. (2016) have analysed a sample group of ResearchGate members, regardless of nationality or affiliation, who have self-selected to follow "supply chain management", in order to determine whether ResearchGate could provide "effective performance indicators" at the researcher level.

\subsection{Statistical analysis of Pakistani LIS scholars}

Scholarly communication is integral to the development and dissemination of research outputs in library and information science (LIS). Within Pakistan, a number of key studies have been published which examine the nature of LIS scholarship. In 1996 Mahmood reported on a review of articles published in foreign journals, which discussed LIS services in Pakistan. More recently, in an effort to understand trends in LIS research in Pakistan, Naseer and Mahmood (2009) have reported on their analysis of articles published between 19982007 in the Pakistan Library \& Information Science Journal; Warraich and Ahmad (2011), for their part, have reported on the results of a similar survey based on the Pakistan Journal of Library and Information Science, now known as the Pakistan Journal of Information Management \& Libraries. Ali and Richardson (2016) have released their findings on the publishing by Pakistani scholars (academics, researchers and professionals) in national LIS and other social science journals.

In 2013 Jan and Anwar reported on the research impact of LIS faculty members in eight Pakistani universities, based on the number of their respective citations in Google Scholar. Whereas Khan and Bhatti (2012), and Sheikh et al. (2016), have examined the use of social media as a marketing tool within Pakistani libraries, Arif and Mahmood (2013), in their study of the adoption of Web 2.0 technologies by Pakistani librarians, have noted the actual use of social networking, particularly Facebook. In their survey of research publishing by Pakistani LIS scholars, Ali and Richardson (2016) have reported that only 29 of 104 respondents (27.88\%) indicated that they did not use any scholarly network.

No study has been conducted to date on the altmetrics associated with Pakistani scholars, let alone those specifically from the LIS discipline. This study is intended to fill that gap. 


\section{Research objectives}

In recent decades, there has been increased attention paid to the changing library and information science (LIS) research environment in Pakistan. Ali and Richardson (2016) have chronicled some of the major studies, particularly those outlining impediments to improving research publishing. Internationally there is interest in not only how scholars use social media as part of their research lifecycle (Bonnand and Hansen, 2013; Tenopir et al., 2013), but also the types of altmetrics generated by social media such as ASNS. This is an area which, although relatively unexplored in relation to Pakistani LIS scholars, offers the potential for useful insights into their research.

To this end, this paper reports on an analysis of the profiles of Pakistani LIS scholars who are members of ResearchGate in terms of the following metrics: publications, reads, citations, RG Score, impact points, topics, "following” and "follower". These metrics will be useful not only for the global LIS community to view the research performance of the Pakistani LIS community, but also for those researchers in other countries and / or disciplines who may wish to conduct a similar study of a defined cohort.

This study focused on the following research questions:

1. How many Pakistani LIS scholars have ResearchGate profiles and associated metrics?

2. How does demographical data for Pakistani LIS scholars in ResearchGate compare with other studies of this cohort?

3. Is there a correlation between the professional seniority of members in this study and the corresponding metrics generated by ResearchGate?

4. What metrics does ResearchGate provide about the impact of publications by Pakistani LIS scholars?

\section{Methodology}

Given the focus on selecting a target group "based on a specific purpose rather than randomly” (Tashakkori and Teddlie, 2003), purposive sampling was selected as the sampling technique. Oliver (2006, p. 244) defines its key concepts and objectives:

A form of non-probability sampling in which decisions concerning the individuals to be included in the sample are taken by the researcher, based upon a variety of criteria which may include specialist knowledge of the research issue, or capacity and willingness to participate in the research. Some types of research design necessitate researchers taking a decision about the individual participants who would be most likely to contribute appropriate data, both in terms of relevance and depth.

The main disadvantages of purposive sampling can be summarized as: vulnerability to errors in judgment by researcher; low level of reliability and high levels of bias; and the inability to generalise research finding (Dudovskiy, 2016). Researcher bias was mitigated by the fact that the the active LIS scholar community is quite small in Pakistan and therefore relatively easily identified. As such, the probability of missing suitable participants among the target population was estimated to be $\pm 1 \%$.

In addition, the following advantages were deemed to outweigh any drawbacks:

- The use of random selection would have increased the possibility of suitable participants being missed

- The desired data could be collected in a short timescale as well as economically 
- The survey questions were specialised and targeted, so specific individuals had to be selected

- Although the data cannot be used as a type of predictor for larger populations, the data from this small sample could be compared later against other similar samples

Purposive sampling was used to collect profiles of all members of ResearchGate who had self-identified as (1) either being located in Pakistan or of Pakistani nationality but temporarily working overseas, and (2) working either in a library / information centre or as a LIS academic. The sampling was undertaken between 15 January 2015 and 30 April 2016. Because of the relatively small size of the target group, most of the scholars within the sample were known personally to the lead author. This meant that demographic data not necessarily included within ResearchGate, e.g. gender and job title, could also be included in this study. For those members who were not known, the authors designed a small survey questionnaire; the responses were collected via Google Docs.

Collected profile data were analysed for this study and various statistical tools were applied in SPSS Version 21.

There are several methodological limitations to the research. First, since RG members must manually add the bibliographical information about their publications, the corresponding number in RG for each member may not represent their actual total outputs. Some scholars eliminated from this study may have published at least one output but have neglected to upload the relevant details to ResearchGate. Second, this study is limited to library professionals and LIS faculty members; LIS students, especially postgraduate, are not represented.

\section{Data analysis}

103 Pakistani LIS scholars had a ResearchGate profile. 25 profiles (24.27\%) did not list any publications and therefore had no "reads"; these were ignored for the purposes of this study, unless otherwise indicated. The remaining 78 profiles $(75.73 \%)$ listed at least one publication.

Following the same methodology as Yu et al. (2016) in their study, this study has used Pearson correlations.

\section{1 Demographical data}

The following demographical information was obtained from the survey questionnaire.

\section{1.1 Gender}

Table I shows that 57 (73.08\%) scholars were male and 21 (26.92\%) were female. In Naseer and Mahmood's study (2009), the ratio was male $=61.0 \%$ and female $=32.2 \%$, with gender not identified for the remaining respondents. The distribution in Table I is very similar to that of Ali and Richardson's (2016) survey, in which male $=74.03 \%$ and female $=25.97 \%$.

Table I. Frequency Distribution by Gender

\begin{tabular}{|l|c|c|}
\hline Gender & Frequency & Percent \\
\hline Male & 57 & 73.08 \\
\hline
\end{tabular}




\begin{tabular}{|l|c|c|}
\hline Female & 21 & 26.92 \\
\hline Total & 78 & 100.00 \\
\hline
\end{tabular}

\subsubsection{Job title}

While one might assume that ResearchGate, by its very name, would only have as members individuals who are either affiliated with a research centre ("researcher") or faculty members, Table II shows that practitioners accounted for the largest percentage of members in this study. Chief Librarians, Deputy Librarians, Assistant Librarians, and Librarians accounted for 50 (64.14\%) members. Faculty members (Professor, Associate Professor, Assistant Professor, and Lecturer) totalled 23 (29.46\%). The “Other” category had 5 (6.4\%) members.

Table II. Frequency Distribution by Job Title

\begin{tabular}{|l|c|l|}
\hline Job Titles & Frequency & Percent \\
\hline Chief Librarian & 3 & 3.85 \\
\hline Deputy Librarian & 9 & 11.54 \\
\hline Assistant Librarian & 11 & 14.10 \\
\hline Librarian & 27 & 34.65 \\
\hline Professor & 2 & 2.55 \\
\hline Associate Professor & 4 & 5.12 \\
\hline Assistant Professor & 14 & 17.95 \\
\hline Lecturer & 3 & 3.84 \\
\hline Other & 5 & 6.40 \\
\hline Total & 78 & 100.00 \\
\hline
\end{tabular}

\subsection{Sector affiliation}

Table III shows that whereas 45 (57.59\%) were affiliated with public universities, 33 (42.31\%) were from private universities. Although the sample population for Ali and Richardson's (2016) survey was larger $(\mathrm{N}=104)$, interestingly nearly the same number of respondents was from the public sector: 30 .

Table III. Frequency Distribution by Sector Affiliation

\begin{tabular}{|l|c|c|}
\hline Institutions & Frequency & Percent \\
\hline Public & 45 & 57.69 \\
\hline Private & 33 & 42.31 \\
\hline Total & 78 & 100.00 \\
\hline
\end{tabular}

\subsubsection{Geographical region}

Three provinces (Punjab, Federal Capital, and Sindh) accounted for 71 (91.02\%) of all Pakistani LIS scholars who had reported at least one publication in ResearchGate (Table IV). There were no members from Baluchistan, Gilgat Baltistan, or Azad Jammu and Kashmir (AJK) who had reported any publications. In Ali and Richardson's (2016) survey, these last 3 regions accounted for only a total of 3 articles, or $0.85 \%$ of the total number of articles 
(354) reported in their survey.

Table IV. Frequency Distribution by Geographic Affiliation

\begin{tabular}{|l|c|c|}
\hline Region & Frequency & Percent \\
\hline Punjab & 46 & 58.97 \\
\hline Federal Capital & 13 & 16.67 \\
\hline Sindh & 12 & 15.38 \\
\hline KPK & 7 & 8.98 \\
\hline Baluchistan & 0 & 0.00 \\
\hline Gilgat Baltistan \& AJK & 0 & 0.00 \\
\hline Total & 78 & 100.00 \\
\hline
\end{tabular}

\subsection{Year of joining ResearchGate}

Those Pakistani LIS scholars who had reported at least one publication in ResearchGate were asked to provide the year in which they had created their initial profile. While active engagement with ResearchGate was quite low between 2012 and 2013, there was an increase of $90.90 \%$, i.e. 20 new members, between 2014 and 2015. This period accounts for $82.05 \%$ of the members represented in the current survey (Table V).

Table V. Frequency Distribution by Year of Joining ResearchGate

\begin{tabular}{|l|c|c|}
\hline Year & Number who joined & Percent \\
\hline 2012 & 2 & 2.56 \\
\hline 2013 & 4 & 5.13 \\
\hline 2014 & 22 & 28.20 \\
\hline 2015 & 42 & 53.85 \\
\hline 2016 & 8 & 10.26 \\
\hline Total & 78 & 100.00 \\
\hline
\end{tabular}

\subsection{Publications}

The following data was extracted from the ResearchGate profiles of the 78 scholars included in this survey.

\subsubsection{Number of publications}

The category publications covers a wide range of outputs: from articles to data to working papers. However, the predominant format is the journal article. In addition, the term as used in ResearchGate can indicate a "metadata only" record, i.e. no file has been uploaded. Since the member must generally manually add the bibliographical information about their publications, the corresponding number may not represent their actual total outputs.

A total of 728 publications had been entered in ResearchGate. Table VI shows the distribution of publications by total number per scholar.

Table VI. Frequency Distribution by Number of Publications per Scholar

\begin{tabular}{|l|c|c|}
\hline $\begin{array}{l}\text { Range of number of } \\
\text { publications per scholar }\end{array}$ & $\begin{array}{c}\text { Number of } \\
\text { scholars }\end{array}$ & Percent \\
\hline $100+$ & 1 & 1.28 \\
\hline
\end{tabular}




\begin{tabular}{|l|c|c|}
\hline $\begin{array}{l}\text { Range of number of } \\
\text { publications per scholar }\end{array}$ & $\begin{array}{c}\text { Number of } \\
\text { scholars }\end{array}$ & Percent \\
\hline $51-99$ & 2 & 2.56 \\
\hline $31-50$ & 0 & 0.00 \\
\hline $11-30$ & 13 & 16.67 \\
\hline $6-10$ & 18 & 23.08 \\
\hline $1-5$ & 44 & 56.41 \\
\hline Total & 78 & 100.00 \\
\hline
\end{tabular}

Just 3 scholars (3.85 \%) accounted for $286(153+81+52)(39.29 \%)$ of the total number of Pakistani LIS scholars' publications listed in ResearchGate. The majority of the scholars in the survey reported between 1 and 5 publications, with 20 (25.64\%) reporting just one publication.

As evidenced by Table VII, there is not a statistically significant correlation between the professional seniority of a scholar and their respective number of publications.

Table VII. Frequency Distribution

\begin{tabular}{|l|c|c|c|}
\hline Job Titles & Frequency & Publications & Percent \\
\hline Chief Librarian & 3 & 12 & 3.85 \\
\hline Deputy Librarian & 9 & 35 & 11.54 \\
\hline Assistant Librarian & 11 & 30 & 14.10 \\
\hline Librarian & 27 & 167 & 34.65 \\
\hline Professor & 2 & 234 & 2.55 \\
\hline Associate Professor & 4 & 35 & 5.12 \\
\hline Assistant Professor & 14 & 166 & 17.95 \\
\hline Lecturer & 3 & 10 & 3.84 \\
\hline Other & 5 & 39 & 6.40 \\
\hline Total & 78 & 728 & 100.00 \\
\hline
\end{tabular}

\subsubsection{Number of reads}

A read is counted when somebody:

- Reads the full-text or summary of any publication on ResearchGate

- Downloads a file hosted on ResearchGate, including direct downloads from Google Scholar and other search engines

A read is not counted when a member accesses one of their own publications.

A total of 36,482 reads were reported by ResearchGate for the 728 publications. As in the case of the number of publications, there was a wide range in values for the number of reads associated with the 78 scholars, i.e. from 1 to 9,000. Table VIII shows the distribution of reads by number per scholar.

Table VIII. Frequency Distribution by Number of Reads per Scholar

\begin{tabular}{|c|c|c|}
\hline $\begin{array}{l}\text { Range of number of reads } \\
\text { per scholar }\end{array}$ & $\begin{array}{c}\text { Number of } \\
\text { scholars }\end{array}$ & Percent \\
\hline $5,000-10,000$ & 2 & 2.56 \\
\hline
\end{tabular}




\begin{tabular}{|c|c|c|}
\hline $\begin{array}{l}\text { Range of number of reads } \\
\text { per scholar }\end{array}$ & $\begin{array}{c}\text { Number of } \\
\text { scholars }\end{array}$ & Percent \\
\hline $3,000-4,999$ & 0 & 0.00 \\
\hline $1,000-2,999$ & 5 & 6.41 \\
\hline $500-999$ & 8 & 10.26 \\
\hline $200-499$ & 19 & 24.36 \\
\hline $100-199$ & 15 & 19.23 \\
\hline $11-99$ & 20 & 25.64 \\
\hline $1-10$ & 9 & 11.54 \\
\hline Total & 78 & 100.00 \\
\hline
\end{tabular}

Nearly half (34, or 43.59\%) of these scholars had between 100 and 500 reads for all their publications.

\subsubsection{Number of citations}

At the time of writing, citations are currently calculated based on those which are extracted from the ResearchGate database. There is no ability to interface with external sources of citation data, although ResearchGate does mention the development of a prototype on its website. From the data that it does have, ResearchGate extrapolates its own $h$-index, based on the work by Hirsch (2005). There are 2 scores provided: (1) including and (2) excluding self-citations.

Of the 78 scholars in the survey, 51 (65.38\%) had at least one citation. The two scholars with the greatest number of publications listed in ResearchGate not only had the highest number of "reads" but also the highest number of citations. There is a positive, but not high, direct correlation between publications and citations as shown in Figure 1. The two aforementioned scholars have been excluded for purposes of readability.

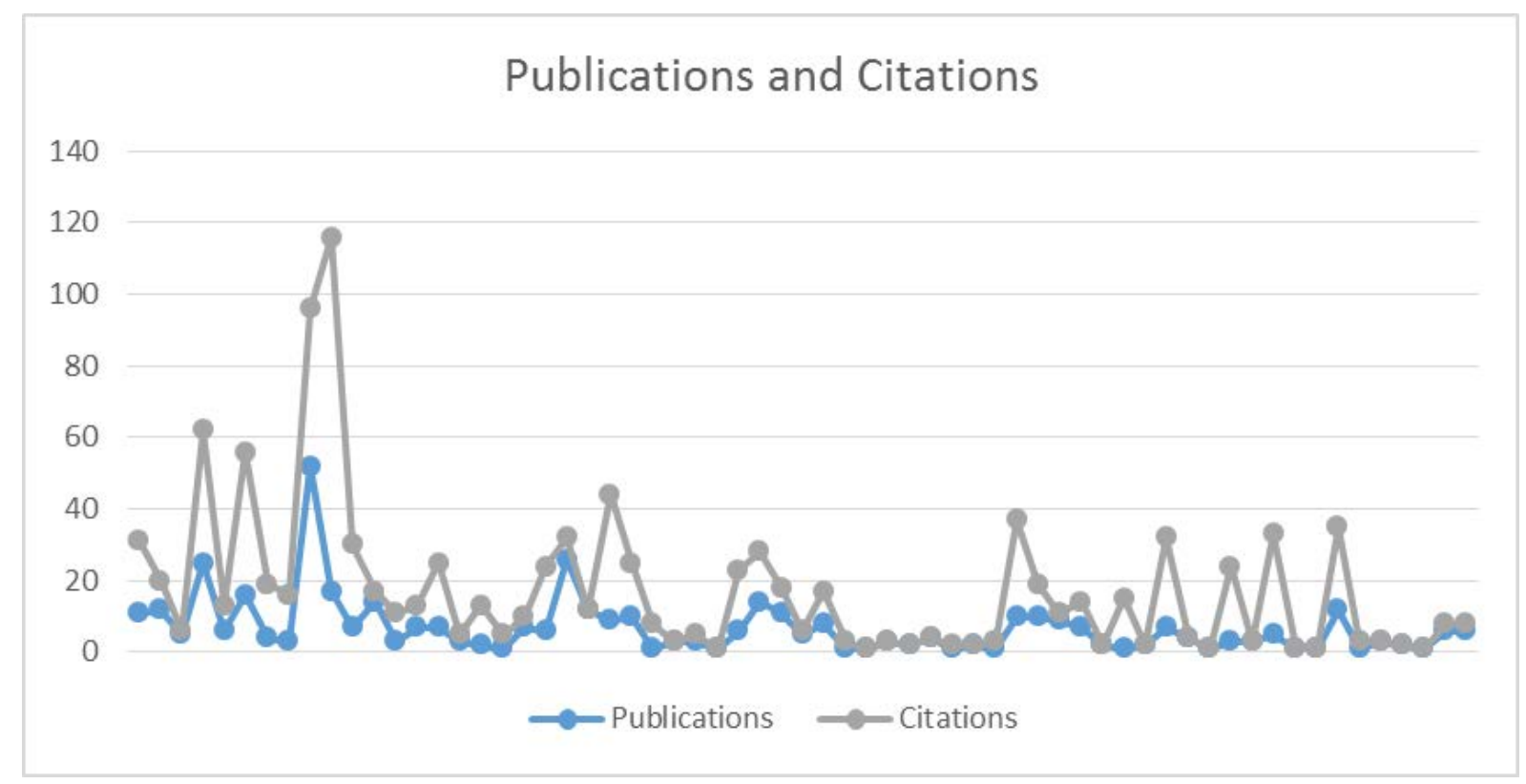

Figure 1: Publications and citations

\subsubsection{Impact points}

At the time of data collection and analysis, ResearchGate was still publishing its score for 
"impact points". As mentioned previously, "impact points" appear to have been based on Thomson Reuter's Web of Knowledge database. According to ResearchGate, it was based on "Journal Impact Factor", which was described on its website as "A quantitative measure of the frequency on average with which articles in a journal have been cited in a given period of time.” Thomson Reuter was not specifically named.

Of the 78 scholars represented in the survey, 34 (43.59\%) had been allocated an "Impact Points" score. Scores ranged from 0.26 to 18.78 with mean $=2.33$ and standard deviation $=$ 3.45 .

\subsection{Followers and following}

Similar to Twitter, for example, ResearchGate provides metrics regarding "follower" and "following":

- Following: The number of other RG members for whom the member will receive updates regarding their publications and contributions on RG

- Followers: The number of RG members who will receive updates about the member's publications and contributions

As with some of the metrics provided thus far, the ranges for these two categories tend to reflect extreme values. On the one hand, the number of followers ranged between 0 and 440 , mean $=30.94 \&$ standard deviation $=51.18$; on the other hand, the number of members whom a scholar was following ranged between 0 and 1072, with a mean $=52.33$ and standard deviation $=135.10$. No significant correlation was found between a scholar's professional seniority and either the number of their respective followers or the number of members being followed.

\subsection{ResearchGate (RG) Score}

The following metric is unique to ResearchGate.

Of the 78 scholars, 45 (57.69\%) had been allocated ResearchGate’s internal RG Score. The score is based on a scholar's "contributions" to ResearchGate, according to which "A contribution is anything you share on ResearchGate or add to your profile". This includes more than publications; for example, additional points can be earned from research questions scholars pose to the ResearchGate community as well as answers they may provide to other scholars' research questions. Scores ranged from 1.21 to 23.83, with a mean $=4.54$ and a standard deviation $=4.22$.

Table IX shows a strong correlation between the RG Score assigned to a scholar and their respective score for Impact Points.

Table IX. Pearson Correlation between Scholars’ RG Score and Impact Points

\begin{tabular}{|cl|r|r|}
\hline & \multicolumn{1}{|c|}{ RG Score } & \multicolumn{1}{c|}{ Impact Points } \\
\hline \multirow{4}{*}{ RG score } & Pearson & 1 & $.903^{* *}$ \\
& Correlation & & \\
& Sig. (2-tailed) & & .000 \\
& $\mathrm{~N}$ & 45 & 45
\end{tabular}




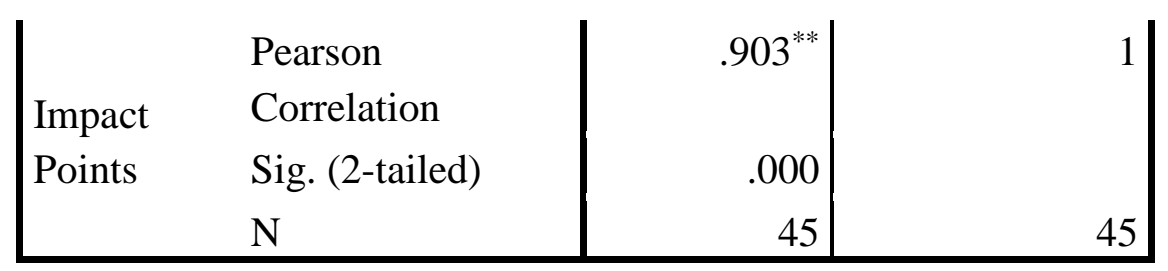

**. Correlation is significant at the 0.01 level (2-tailed).

\subsection{Topics}

ResearchGate members have the option to follow topics of interest. The 78 scholars represented in the survey have followed total 65 different topics, of which the following five account for 35.23\%: qualitative social research, quantitative social research, communication and media, information science, and social science. A maximum of 9 topics was followed by a single scholar. Figure 2 illustrates the breadth of topics followed.

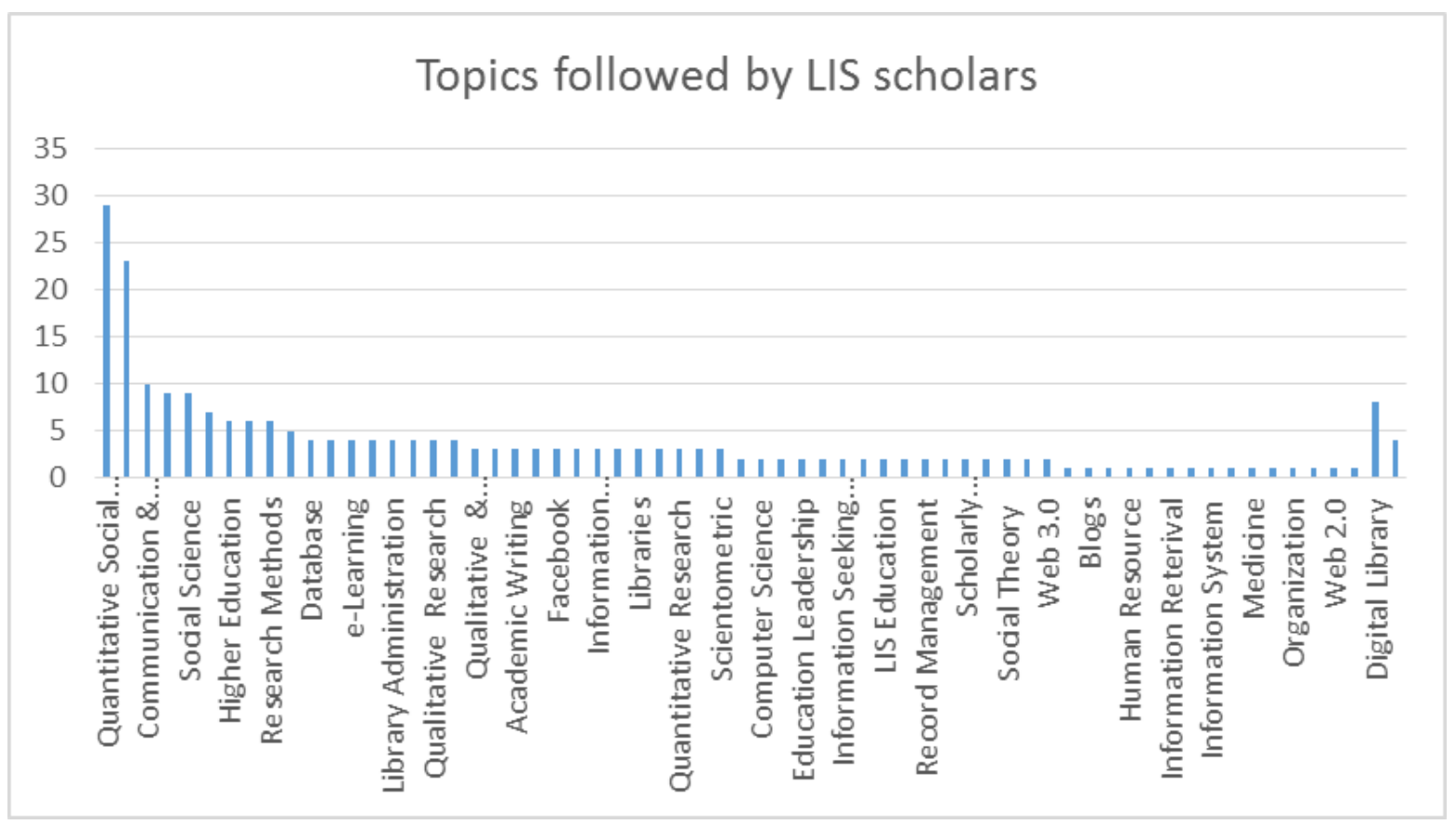

Figure 2: Topics followed by Pakistani LIS scholars

\section{Discussion}

This research has examined the profiles of Pakistani LIS scholars who are members of ResearchGate in terms of the site's key metrics. In general, demographical data for this group was comparable with other studies of this same cohort. Survey results continue to show the clear dominance of males. Ali and Richardson (2016, p. 15) have suggested that "This gender distribution would seem to reflect the fact that in Pakistani culture many women do not continue to study after marriage. It can be challenging for female professionals to continue undertaking research once they have family and household responsibilities”.

The predominance of three provinces (Punjab, Federal Capital, and Sindh) and public institutions in terms of geographical and sector affiliation reflects the overall pattern of distribution of Pakistani universities. For example, in a study by Jan and Anwar (2013), the 
University of the Punjab, a public institution, alone accounted for $83.9 \%$ of the publications by LIS faculty from eight Pakistani universities.

In all of the categories examined in this study (publications, reads, citations, RG score, impact points, followers, and following), one scholar -a senior academic-- consistently had the highest score. Even if the publications listed for that member's profile do not represent their total body of work, the number of publications listed in ResearchGate far exceeded even that of the closest score. Another senior academic had the second highest scores for the categories of publications, reads, citations and RG score. Since the RG score relies heavily on scores in the first three categories, this correlation is not surprising. Aside from these two outliers, however, no statistically significant correlation was found between the professional seniority of a scholar and their respective number of publications. This finding affirms the result which Ali and Richardson reported in their 2016 survey.

In addition, the distribution of the total number of publications per scholar is indicative of the Pareto Principle, i.e. the majority of results come from a minority of inputs. It is also consistent with the distribution of outputs from academic institutions. As Glance (2012) observes, “... academic publication also follows a long tail distribution. A relatively few academics produce a lot of work each year and the majority (80\%) produce very much less, perhaps 1 or 2 outputs a year”. In the current study, one-quarter of the scholars had reported just one publication, with a little over half reporting between one and five publications.

Despite ResearchGate having ceased to publish its own impact scores after the authors' study had been completed, the data gained from the survey was useful. ResearchGate's impact points were based on a very traditional paradigm, i.e. journal impact factor. The fact that less than half of the 78 scholars represented in this study had been allocated an impact points score would seem to indicate that the major portion of publications of this cohort had not been published in a journal which had been assigned an impact factor (IF) ranking by Thomson Reuters. Given the relatively low scores in general for those who did receive one, it would appear that few articles had been published in high ranking IF journals. Jan and Anwar (2013), for their part, have reported the relative non-visibility of Pakistani LIS outputs published in local languages and / or non-impact-factor journals.

Although ResearchGate's category of citations relies on internal data, i.e. citations retrieved from publications uploaded to the ResearchGate database, the results of the study show that there is no correlation between whether a scholar is an academic or a practitioner and their corresponding number of citations. Further investigation would be useful to compare ResearchGate metrics for both those sub-groups within the LIS scholar cohort. For example, one could test the hypothesis that publications by practitioners would have more of a "practice focus" and therefore would attract more reads than citations when compared with publications by academics.

Whereas there was no discernible statistical pattern in terms of the categories of followers and following, the potential usefulness of knowing whom Scholar $\mathrm{X}$ follows is that it is one method for identifying additional publications which might be of interest. The principle is similar to that of the Amazon Recommendation: people who liked ABC will probably also like XYZ (Pazzani and Billsus, 2007). Therefore, from a research discovery perspective, it broadens the available resources for a scholar's particular area of interest.

As noted by Naseer and Mahmood (2014) in their study, the research interests among Pakistani LIS academics have begun to expand beyond the traditional "library and information science", but there is scope for improvement. While the breadth of topics followed by scholars in the current study does not necessarily equate to future publications in those areas, these results suggest the potential for more interdisciplinary research. 
In terms of the immediate implications of this study, it would be advantageous to promote the use of ASNS, especially to new Pakistani LIS scholars; the potential benefits are twofold. First, since, as discussed previously, social media sites have been found to be a significant source of free articles in lower income countries, scholars may have access to scholarly resources not normally available in their institution. Second, establishing a public professional profile creates the potential for collaboration, building connections, and exchanging information and ideas. Therefore ASNS offer a potential vehicle for assisting Pakistan's national strategic objectives to improve research publishing.

At the same time, the analysis of survey data has assisted in identifying additional areas which require investigation. First, the much higher proportion of librarians $(64.14 \%)$ represented in the survey as compared with academics / researchers (35.86\%) raises fundamental questions as to (1) the primary motivations for which these respective subgroups have become members of RG and (2) the principal features of RG which they use. Further research is indicated in investigating the usage of RG specifically, as well as ASNS in general, by LIS scholars, with a particular focus on motivation. It would be useful to know whether there are any linkages between the two sub-groups. For example, do librarians use ASNS to keep-up-to-date with research not only in librarianship but also in the disciplines they support within their institution?

An additional area for potential further investigation would be to determine whether those Pakistani LIS scholars who have a ResearchGate profile also have other ASNS profiles, e.g. Google Scholar, Academia.edu, and Kudos. This research is needed to inform our understanding of the role which ASNS may be considered to play in the scholarly communication lifecycle.

Just as importantly, it will help to inform an institution how best to support its scholars. Library staff will want to know if resource discovery, e.g. downloading full-text content from an ASNS, is an important driver of use, since this has potential implications for how the library financially supports research areas of strategic importance to the institution. If, on the other hand, creating a public profile in order to improve one's research is a primary motivator, then several key stakeholders within the institution would benefit from this knowledge, in particular, the library, postgraduate supervisors, research centre directors, and heads of departments / faculties. While the library has a role to play in advising about best practice in creating an effective academic profile, the other stakeholders will want to ensure that the use of an ASNS, especially by early career researchers and postgraduate students, forms part of an overall planned approach to developing a publishing strategy which will increase the visibility and impact of one's research.

\section{Conclusion}

The scholarly information lifecycle has traditionally focused on the published article or book as the key output of the process. However, the growth of social media and networked technologies has enhanced that cycle by including methods of dialogue and output such as blogs, podcasts, and networking sites. These expand the reach of a scholar's ideas in new and, very importantly, interactive ways.

ResearchGate (RG) has become one of the most popular academic social networking sites (ASNS). The current research has shown that while the uptake by a designated cohort-Pakistani library and information science scholars-- has been relatively low, the site appears to have offered some benefits for those who have done so. Significantly, while all respondents had at least one "read" for publication details which they have uploaded, the majority had in excess of 100 reads. This demonstrates the role which RG plays in 
expanding the reach of this cohort's publications, as well as the ability to create a public professional profile.

Additional research could further enlighten the specific ways in which ASNS in general currently support not only LIS scholars but also those from other disciplines in other stages of the scholarly communication lifecycle.

\section{References}

Alhoori, H., Furuta, R., Tabet, M., Samaka, M. and Fox, E. A. (2014), "Altmetrics for country-level research assessment”, in Tuamsuk, K., Jatowt, A. and Rasmussen, E. (Eds.), The Emergence of Digital Libraries-Research and Practices, Springer International Publishing, Heidelberg, pp. 59-64.

Ali, M.Y and Richardson, J. (2016), "Research publishing by library and information science scholars in Pakistan: a bibliometric analysis", Journal of Information Science Theory and Practice, Vol. 4 No. 1, pp. 6-20.

Arif, M. and Mahmood, K. (2012), "The changing role of librarians in the digital world: Adoption of Web 2.0 technologies by Pakistani librarians”, The Electronic Library, Vol. 30 No. 4, pp. 469-479.

Asnafi, A.A., Salami, M., Sayyah, B.M. and Hosseini, A.S.A. (2015), "Presence of Ahvaz universities (medical science, Azad and governmental) scholars Iranian library and information science scholars in academic social network: Research Gate”, Educational Development of Jundishapur, Vol. 6 No. 5, pp. 67-73.

Association of Research Librarians (ARL) (n.d). Scholarly communication, available at: http://www.arl.org/focus-areas/scholarly-communication\#.VVWa2EZ5lmM (accessed 30 June 2016).

Chakraborty, N. (2012), “Activities and reasons for using social networking sites by research Scholars in NEHU: A study on Facebook and ResearchGate", paper presented at 8th Convention PLANNER-2012, 1- 3 March, Sikkim University, Gangtok, India, available at: http://ir.inflibnet.ac.in/handle/1944/1666 (accessed 30 June 2016).

Crawford, M. (2011), "Biologists using social-networking sites to boost collaboration”, BioScience, Vol. 61 No. 9, p. 736.

Dudovskiy, J. (2016). "Purposive sampling", available at: http://researchmethodology.net/sampling-in-primary-data-collection/purposive-sampling/ (accessed 14 December 2016)

Durieux, V. and Gevenois, P.A. (2010), "Bibliometric indicators: quality measurements of scientific publication”, Radiology, Vol. 255 No. 2, pp. 342-351.

Ellison, N. B. and Boyd, D. (2013), "Sociality through social network sites", in Dutton, W. (Ed.), The Oxford Handbook of Internet Studies, Oxford University Press, Oxford, pp. 151-172.

Elsayed, A. M. (2016), "The use of academic social networks among Arab researchers a survey”, Social Science Computer Review, Vol 34 No. 3, pp. 378-391.

Espinoza Vasquez, F. K. and Caicedo Bastidas, C. E. (2015), “Academic social networking sites: a comparative analysis of their services and tools" in iConference 2015 Proceedings, available at: http://hdl.handle.net/2142/73715 (accessed 30 June 2016).

Garcia-Milian, R. \& Norton, H.F. (2013), "Provision of online reference through ResearchGate”, Journal of the Medical Library Association, Vol. 101 No. 4, p. 242.

Gardner, T. and Inger, S. (2016), How Readers Discover Content in Scholarly Publications: Trends In Behaviour From 2005 To 2015, Renew Training: Oxford. 
Giglia, E. (2011), “Academic social networks: it's time to change the way we do research”, European Journal of Physical and Rehabilitation Medicine, Vol. 47 No. 2, pp. 345-349.

Glance, D. (2012), “The long tail of academic publishing and why it isn't a bad thing”, The Conversation, 8 July, available at: http://theconversation.com/the-long-tail-of-academicpublishing-and-why-it-isnt-a-bad-thing-8126 (accessed 30 June 2016).

Goodwin, S., Jeng, W. and He, D. (2014), "Changing communication on ResearchGate through interface updates", Proceedings of the American Society for Information Science and Technology, Vol. 51 No. 1, pp. 1-4.

Goodyear, R. K., Brewer, D. J., Gallagher, K. S., Tracey, T. J., Claiborn, C. D., Lichtenberg, J. W. and Wampold, B. E. (2009), "The intellectual foundations of education core journals and their impacts on scholarship and practice”, Educational Researcher, Vol. 38 No. 9, pp. 700-706.

Groos, O. V. and Pritchard, A. (1969), “Documentation notes”, Journal of Documentation, Vol. 25 No. 4, pp. 344-349.

Haunschild, R., Bornmann, L. and Leydesdorff, L. (2015), "Networks of reader and country status: an analysis of Mendeley reader statistics”, PeerJ Computer Science, Vol. 1, e32, available at: http://dx.doi.org/10.7717/peerj-cs.32 (accessed 30 June 2016).

Haustein, S. and Siebenlist, T. (2011), "Applying social bookmarking data to evaluate journal usage”, Journal of Informetrics, Vol. 5 No. 3, pp. 446-457.

Haustein, S., Peters, I., Bar-Ilan, J., Priem, J., Shema, H. and Terliesner, J. (2014), “Coverage and adoption of altmetrics sources in the bibliometric community", Scientometrics, Vol. 101 No. 2, pp. 1145-1163.

Hoffmann, C. P., Lutz, C. and Meckel, M. (2016), “A relational altmetric? Network centrality on ResearchGate as an indicator of scientific impact”, Journal of the Association for Information Science and Technology, Vol. 67 No. 4, pp. 765-775.

Howard, J. (2013), "Posting your latest article? You might have to take it down”, Chronicle of Higher Education, Vol. 60 No. 16, p. A12.

Jan, S. U. and Anwar, M. A. (2013), "Impact of Pakistani authors in the Google world: a study of library and information science faculty", Library Philosophy and Practice (ejournal), paper 980, available at: http://digitalcommons.unl.edu/libphilprac/980/ (accessed 30 June 2016).

Jordan, K. (2015), "Exploring the ResearchGate score as an academic metric: reflections and implications for practice", paper presented at Quantifying and Analysing Scholarly Communication on the Web (ASCW'15), 30 June 2015, Oxford, available at: http://oro.open.ac.uk/id/eprint/43538 (accessed 30 June 2016).

Kadriu, A. (2013), "Discovering value in academic social networks: A case study in ResearchGate”, in Luzar-Stiffler, V. and Jarec, I. (Eds), Proceedings of the ITI 2013 35th International Conference on Information Technology Interfaces (ITI), University of Zagreb, Croatia, pp. 57-62.

Khan, S. A. and Bhatti, R. (2012), "Application of social media in marketing of library and information services: A case study from Pakistan”, Webology, Vol. 9 No. 1, pp. 1-8, available at: http://www.webology.org/2012/v9n1/a93.html (accessed 30 June 2016).

Kraker, P. and Lex, E. (2015), “A critical look at the ResearchGate score as a measure of scientific reputation", in Proceedings of the Quantifying and Analysing Scholarly Communication on the Web workshop (ASCW'15), Web Science conference.

Kraker. P, Jardon, K. and Lex. E. S. (2015), "ResearchGate score: good example of a bad metric”, Social science space (blog), 11 December, SAGE Publications, Thousand Oaks, Ca, available at: http://www.socialsciencespace.com/2015/12/researchgate-score-goodexample-of-a-bad-metric/ (accessed 30 June 2016). 
Li, X., Thelwall, M. and Giustini, D. (2011), "Validating online reference managers for scholarly impact measurement”, Scientometrics, Vol 91 No 2, pp. 461-471.

Madhusudhan, M. (2012), "Use of social networking sites by research scholars of the University of Delhi: A study”, The International Information \& Library Review, Vol. 44 No. 2, pp. 100-113.

Mahajan, P., Singh, H. and Kumar, A. (2013), "Use of SNSs by the researchers in India: A comparative study of Panjab University and Kurukshetra University”, Library Review, Vol. 62 No. 8/9, pp. 525-546.

Mahmood, K. (1996), "Library and information services in Pakistan: a review of articles published in foreign journals”, The International Information \& Library Review, Vol. 28 No. 4, pp. 383-405

Mas-Bleda, A., Thelwall, M., Kousha, K. and Aguillo, I. F. (2014), "Do highly cited researchers successfully use the social web?”, Scientometrics, Vol. 101 No. 1, pp. 337356

Mikki, S., Zygmuntowska, M., Gjesdal, Ø. L. and Al Ruwehy, H. A. (2015), "Digital presence of Norwegian scholars on academic network sites-where and who are they?", PLOS ONE, Vol. 10 No. 11, e0142709, available at: http://dx.doi.org/10.1371/journal.pone.0142709 (accessed 30 June 2016).

Naseer, M. M. and Mahmood, K. (2009), "LIS research in Pakistan: an analysis of Pakistan Library and Information Science Journal 1998-2007”, Library Philosophy and Practice, 2009 (June), unpaginated, available at: http://hdl.handle.net/10760/13803 (accessed 30 June 2016).

National Information Standards Organization. (2016), Altmetrics Data Quality Code of Conduct (NISO RP-25-201X-3), NISO, Baltimore, MD.

Nentwich, M. and König, R. (2012), Cyberscience 2.0: Research in the Age of Digital Social Networks (Vol. 11), Campus Verlag, Frankfurt.

Newton, H. (2013), "Breaking boundaries in academic publishing: launching a new format for scholarly research”, Insights, Vol. 26 No. 1, pp.70-76.

Neylon, C., Willmers, M. and King, T. (2014), Rethinking impact: Applying altmetrics to southern African research, Paper 1, Scholarly Communication in Africa Programme, Cape Town, available at:

http://openuct.uct.ac.za/sites/default/files/media/SCAP_Paper_1_Neylon_et_al_Rethinki ng_Impact.pdf (accessed 30 June 2016).

Nicholas, D., Herman, E. and Jamali, H. R. (2015), Emerging Reputation Mechanisms for Scholars, Publications Office of the European Union, Luxembourg.

Nielsen, M. (2012), Reinventing Discovery: The New Era of Networked Science, Princeton University Press, Princeton, NJ.

Oliver, P. (2006), "Purposive sampling”, in Jupp, V. (Ed.), The Sage Dictionary of Social Research Methods, Sage Publication, London, pp. 244-245.

Onyancha, O. B. (2015), "Social media and research: an assessment of the coverage of South African universities in ResearchGate, Web of Science and the Webometrics Ranking of World Universities”, South African Journal of Libraries and Information Science, Vol. 81 No. 1, pp. 8-20.

Ortega, J. L. (2015a), "Disciplinary differences in the use of academic social networking sites”, Online Information Review, Vol. 39 No. 4, pp. 520-536.

Ortega, J. L. (2015b), "How is an academic social site populated? A demographic study of Google Scholar Citations population”, Scientometrics, Vol. 104 No. 1, pp. 1-18.

Ortega, J. L. (2015c), "Relationship between altmetric and bibliometric indicators across academic social sites: The case of CSIC's members", Journal of Informetrics, Vol. 9 No. 1, pp. 39-49. 
Ovadia, S. (2014), "ResearchGate and Academia.edu: Academic social networks", Behavioral \& Social Sciences Librarian, Vol. 33 No. 3, pp. 165-169.

Pazzani, M. J. and Billsus, D. (2007), "Content-based recommendation systems", in Brusilovsky, P., Kobsa, A. and Nejdl, W. (Eds.), The Adaptive Web, Springer-Verlag, Berlin, pp. 325-341.

Phillips, A. (2013), “Business models in journals publishing”, Logos, Vol. 24 No. 4, pp. 2435.

Ponte, D. and Simon, J. (2011), "Scholarly communication 2.0: Exploring researchers' opinions on Web 2.0 for scientific knowledge creation, evaluation and dissemination", Serials Review, Vol. 37 No. 3, pp. 149-156.

Priem, J., Piwowar, H. A. and Hemminger, B. M. (2012), "Altmetrics in the wild: Using social media to explore scholarly impact”, arXiv preprint arXiv:1203.4745.

Rinaldi, A. (2014), "Spinning the web of open science”, EMBO Reports, Vol. 15 No. 4, pp. 342-346.

Roemer, R. C. and Borchardt, R. (2012), "From bibliometrics to altmetrics: A changing scholarly landscape”, College \& Research Libraries News, Vol. 73 No. 10, pp. 596-600.

Sample, I. (2012), “Harvard University says it can’t afford journal publishers' prices”, The Guardian, 24 April, available at:

http://www.iimas.unam.mx/biblio/contenidoEstatico/archivo/files/Biblioteca/Harvard.pdf (accessed 30 June 2016)

Sheikh, A., Syed, K.A. and Naseer, M.M. (2016), "Use of social media tools by reputed University libraries of the world: a comparative study”, Pakistan Journal of Library and Information Science, Vol. 47 No. 2, pp. 45-54.

Smith, A. G. (2004), “Web links as analogues of citations”, Information Research, Vol. 9 No. 4, paper 188, available at: http://informationr.net/ir/9-4/paper188.html (accessed 22 March 2016).

Tashakkori, A. and Teddlie, C. (Eds.), (2003). Handbook of Mixed Methods in Social \& Behavioral Research, Sage, Thousand Oaks, CA.

Thelwall, M. and Kousha, K. (2016), "ResearchGate articles: Age, discipline, audience size, and impact", Journal of the Association for Information Science and Technology, ["Early view”], available at: dx.doi.org/10.1002/asi.23675 (accessed 30 June 2016)

Thelwall, M. and Kousha, K. (2014), “Academia. edu: social network or academic network?” Journal of the Association for Information Science and Technology, Vol. 65 No. 4, pp. 721-731.

Thelwall, M. and Kousha, K. (2015), "ResearchGate: Disseminating, communicating, and measuring scholarship?" Journal of the Association for Information Science and Technology, Vol. 66 No. 5, pp. 876-889.

Van Noorden, R. (2014), “Online collaboration: Scientists and the social network”, Nature, Vol. 512 No. 7513, pp. 126-129.

Vaughan, L. and Shaw, D. (2004), "Can web citations be a measure of impact? An investigation of journals in the life sciences", Proceedings of the American Society for Information Science and Technology, Vol. 41 No. 1, pp. 516-526.

Veletsianos, G. (2016), Social Media in Academia: Networked Scholars, Routledge, New York.

Warraich, N. F. and Ahmad, S. (2011), "Pakistan Journal of Library and Information Science: A bibliometric analysis”, Pakistan Journal of Library \& Information Science, No. 12, pp. 1-7.

White, C., Plotnick, L., Kushma, J., Hiltz, S. R. and Turoff, M. (2009), “An online social network for emergency management”, International Journal of Emergency Management, Vol. 6 No. 3-4, pp. 369-382. 
Wildgaard, L., Schneider, J. W. and Larsen, B. (2014), “A review of the characteristics of 108 author-level bibliometric indicators”, Scientometrics, Vol. 101 No. 1, pp. 125-158.

Wilsdon, J. et al. (2015), The Metric Tide: Report of The Independent Review of The Role of Metrics in Research Assessment and Management, available at: http://dx.doi.org/10.13140/RG.2.1.4929.1363 (accessed 30 June 2016).

Yu, M. C., Wu, Y. C. J., Alhalabi, W., Kao, H. Y. and Wu, W. H. (2016), "ResearchGate: An effective altmetric indicator for active researchers?”, Computers in Human Behavior, Vol. 55, pp. 1001-1006. 